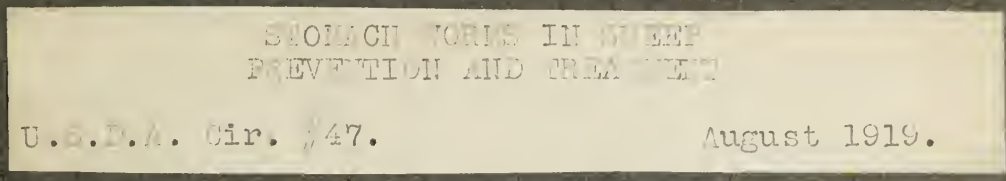

\title{
$\mathrm{SF}$ 810 $W_{6} 57$
}

UC-NRLF

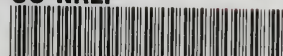

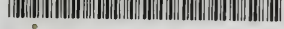

В 3 109 190 


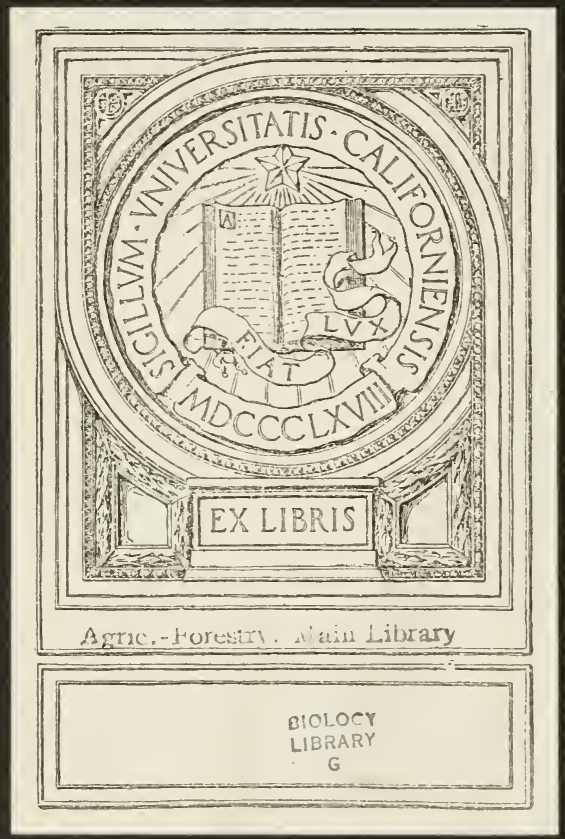




\title{
STOMACH WORMS IN SHEEP
}

\section{PREVENTION AND TREATMENT}

\author{
Prepared Jointly by the Animal Husbandry \\ and Zoological Divisions
}

UNITED STATES DEPARTMENT OF AGRICULTURE DEPARTMENT GIRCULAR 47

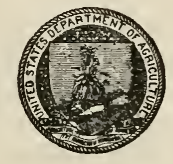


$\because \because \because \quad \vdots \because \vdots \vdots: \vdots \vdots \vdots$

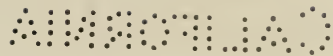

\section{Hox $0-r$ \\ (c) \\ U}

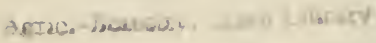




\section{STOMAGH WORMS IN SHEEP:}

\section{PREVENTION AND TREATMENT.}

CONTENTS.

Page.

How can one tell when sheep have stomach worms?.................................. 3

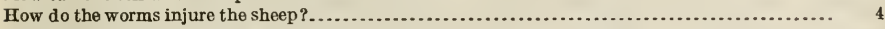

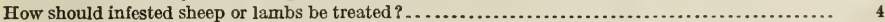

How do sheep become infested by stomach worms ? .................................... 6

What methods can be employed to prevent loss from stomach worms? ...................... 8

NE of the most serious problems of owners of farm sheep is the prevention of injury and loss by stomach worms. This parasite (Hæmonchus contortus) has been known in this country for many years and is common in farm flocks, particularly during wet summers. It has been studied by the Zoological Division of the Bureau of Animal Industry and the principal facts in its life history have been determined. Methods of treatment and of prevention are still under investigation by that division, and although the methods have not yet been perfected, what has been learned is sufficient to show how affected sheep or lambs can be treated successfully and, what is of greater importance, how they may be raised in such a way as practically to overcome the danger.

What is known of this parasite and the methods of prevention and control may be presented as answers to practical questions, as follows:

\section{HOW CAN ONE TELL WHEN SHEEP HAVE STOMACH WORMS?}

Either lambs or old sheep may be affected by stomach worms at any time of the year. The trouble may be noticed first in lambs about the middle of summer, though it may be earlier, according to the part of the country and the temperature and moisture of the season.

In many flocks the first knowledge of the trouble is gained through the death of one or more lambs. If the flock is under careful observation, however, signs of stomach-worm disease will be noticed earlier. Dullness and lack of thrift are among the first indications. Scouring is often present. These conditions may result from other causes, but when due to stomach worms, they are accompanied with a very pale, bloodless appearance of the skin and of the mucous membranes of the eyes and mouth. The whiteness of the skin has caused the trouble to be known in some sections as "paper skin." In many cases there is a watery swelling under the jaws. 
Doubt as to the cause of the trouble can be remored by an examination of the fourth stomach. For examination purposes, any one unfamiliar with the ailment can well afford to kill an uffected lamb. If there is any uncertainty as to the position of the fourth stomach it can be ascertained by taking hold of any part of the small intestine and following it forward. The fourth stomach is one of the 4 compartments into which the stomach is divided and is the portion continuous with the forward end of the small intestine. When the fourth stomach is found, it should be held so as to prevent the fluids from leaving it at either end, and an incision made along nearly the full length of the upper part. When this is done the stomach worms, if present, can be seen, often in large numbers, wriggling around in the fluids. They are from one-half to 11 inches long, about as thick as an ordinary pin, and spirally striped with red and white. It is often necessary to look closely for some time in order to distinguish them. When the stomach is emptied some of the worms can be seen adhering to the inside walls.

\section{HOW DO THE WORMS INJURE THE SHEEP?}

The injurious action of the stomach worms may be attributed to two things: First, the loss of blood abstracted by the parasites, and second, the destruction of red corpuseles by a poisonous substance which is secreted by the parasites and taken up by the blood. Evidently the older, stronger, and larger sheep are better able than the lambs to withstand the loss of blood, and can better endure the loss due to the destruction of red corpuseles. Furthermore, in the blood of adult sheep there may be substances tending to neutralize the poisonous matter produced by the parasites that are absent from the blood of lambs, or that, if present, oceur in smaller quantities. Besides the direct injury eaused by stomach worms it is not unlikely that damage is also done by bacterial infection through tho wounds the worms make in the mucous lining of the stomach.

\section{HOW SHOULD INFESTED SHEEP OR LAMBS BE TREATED?}

\section{MEDICINAL TREATMENT.}

If taken in time, most cuses of stumach worms can bo troated successfully uccording to the following directions:

Dissolve one-fourth pound (avoirdupois) of the powdered erystals of copper sulphate (bluestone) in 1 pint of boiling water, using a porcelain or enamel-ware dish, as the bluestono corrodes most metals. Then udd cold water enough to make the solution up to 3 grallons, using wooden, enrthenware, or other nommetnllic receptacles. This will unke upproximately a 1 per cent solution and will be onough to dose 100 adult sheep, allowing 10 per cont waste. In the preparation of the dese use only clear-hluo crystals of copper sulphate. ('rush the crystals to a fine powder when ready to mulo up tho solution. 
The doses for lambs and sheep are:

For lambs under 1 year of age............... $1 \frac{3}{4}$ ounces ( 50 cubic centimeters).

For sheep past 1 year old.................. $3 \frac{1}{2}$ ounces ( 100 cubic centimeters).

A glass with marks scratched on the side with a file may be used for measuring the doses.

The drenching apparatus consists of (1) a strong rubber tube about 3 feet long and three-eighths inch in diameter; (2) a hard rubber, porcelain, or enamel-ware funnel, which is fastened to one end of the tube; and (3) a brass mouthpiece three-eighth inch in diameter and 9 inches long, fastened to the other end. It is preferable that the end of this tube should be closed and holes made in the sides of about the last two inches of its length.

Ordinarily the treatment is given after the sheep have been without feed overnight, but apparently it may be given with equally good results without preliminary fasting, provided the animals are not gorged with feed or water when treated. For best results sheep should not be watered for 2 hours afterwards.

While being drenched the sheep should remain on all 4 legs with its head held horizontally. This is important, for if the head is held above the horizontal (nose higher than the eyes), there is danger that some of the fluid will pass into the lungs, thereby causing pneumonia and almost certain death. Measure the dose in the measuring glass, and after the drenching tube is in position pour the dose slowly into the funnel. The metal mouthpiece of the drenching tube should be placed between the jaws in the space between the teeth at the side of the mouth and directed backward, but should not reach farther than the base of the tongue. In order to prevent the sheep from stopping up the end of the mouthpiece with its tongue and thus interfering with the flow of the liquid, the person holding the mouthpiece in the sheep's mouth should give it a rotary motion. This tends to keep the sheep swallowing, prerents plugging the tube, and also tends to keep the fluid from entering the lungs. The fluid should not be administered more rapidly than the sheep can swallow comfortably.

Care in the administration of the dose is highly important, as carelessness or any undue haste is liable to have serious results. The copper-sulphate treatment, like the administration of medicines in general, is safest in the hands of a competent veterinarian.

\section{CHANGE OF PASTURE NECESSARY FOR BEST RESULTS.}

Although losses from stomach worms in many cases may be minimized by repeated medicinal treatment without change of pasture, much better results can be obtained if the treated animals are placed on ground that is free or practically free from infection. It is still better to institute preventive measures before the results of stomach-worm infection become evident. A lamb that has been 
affected sufficiently to show the external effects of stomach worms has received a serious setback. Although it may recover and again be thrifty it has lost at least a month or 6 weeks of progress toward marketable weight and condition. The only safe and economical way of raising sheep where stomach worms are a factor is by managing the flock and pastures in a way to prevent a serious development of the trouble. In most localities the methods necessary for preventing stomach worms are at the same time those that need to be employed for most economical production. In order to follow these methods, particularly with respect to pasture rotation, the shepherd needs to know just how and when infection oceurs.

\section{HOW DO SHEEP BECOME INFESTED BY STOMACH WORMS?}

INFESTED PASTURES.

In the adult sexual stage stomach worms are able to live and carry out their reproductive functions only in the alimentary canal of sheep or other ruminants, and practically only in the fourth stomach. Each female produces thousands of eggs, of microscopic size, which do not develop into adult worms in the body of the host in which they are deposited, but, without hatching, pass out of the intestime in the feces. In a few hours, days, or weeks, according as the temperature is high or low, these eggs, if they are not killed by drying or freezing (either of which is commonly fatal to them), hatch and the tiny embryonic stomach worms then develop to what may be termed the final larval or infectious stage. 'This later development likewise requires days or weeks, according to the temperature, and until the young worms have reached the infectious stage they appear to be fully as susceptible to freezing and drying as the eggs. Having reached the infectious stage, however, the worms are able to withstand long periods of dryness and severe cold, though some of them succumb comparatively early.

In the infeetious stage the young worms are very active in the presence of moisture, and rapilly orawl up bludes of grass and other objects whenever the relative humidity of the air is at a maximum, provided the temperature is above $40^{\circ} \mathrm{F}$. or theroabout; below that temperature they are inactive. A decronso in the relative humidity, with the consecquent evaporation of the moisture from the surface of grass blades and other objects, stops the migrations of tho worms, and they becomo quiescent and remain in a condition of suspended animation wherever they happen to be at the time. During the noxt period of wet woather, dew, rain, or fog, the worms again beome active and climb still higher on the grass, from which they are better able to attain their final abode within the stomash of a sheep or cow than if they remaned on the ground. When swullowed by a sheep or other ruminant tho young stomach worm, if it has reached its final 
larval stage, whether active at the time or in a state of suspended animation, continues its development, and in the course of 2 or 3 weeks reaches maturity.

The length of life of individual worms in the stomach has not been determined. Infested sheep have been kept in pens with board floors, which were kept clean by sweeping and frequent serubbingthe sheep being fed from raised racks and water being supplied in a trough which was frequently eleaned-for varying periods up to a maximum of 19 months, and at the end of these periods were found to be still infested, though the number of worms present was small.

As the possibility of reinfection by larval worms developing from eggs passed in the feces of these sheep was not entirely removed, though greatly minimized, the results obtained do not necessarily indicate that the worms found at the end of the period of observation were all present when the experiment was begun. The experiment, however, while it proves nothing as to the length of life of the adult stomach worm, demonstrates the futility of attempting to rid sheep entirely of stomach worms simply by keeping them away from pasture. On the other hand, very little infection oocurs among sheep kept in stables if cleanly conditions are maintained. Lambs have been kept with infested sheep in stables for long periods of time, the only precautions against infection being the removal of manure about once a week. Under such conditions they have continued in good health, and aequired only a very few stomach worms and other parasites.

\section{LENGTH OF TIME PASTURES MAY BE INFESTED.}

The maximum period during which the larval stomach worms are able to survive on pastures is not definitely known, but it has been found that pastures on which infested sheep had grazed were apparently still infectious after a lapse of neariy 8 months, namely, from October 25 , when the infested sheep were removed, to June 16 , when the pastures were tested by placing in them some lambs which had been raised under special precautions to avoid previous infestation. In cultures made September 14, 1906, from the feces of an infested sheep and kept thereafter in the laboratory, most of the larvæ were dead but some were still alive, though very sluggish, on June 5, 1907, nearly 9 months later. Cultures in which the worms were allowed to develop to the final larval stage, after they were kept in cold storage at a temperature below freezing -in some cases as low as $12^{\circ} \mathrm{F}$.still oontained some living worms after 2 or 3 months, while in other oultures eggs and newly hatched worms not yet developed to the final larval stage were killed within a few hours after exposure to temperatures below freezing.

These experiments show that pastures may remain infected for several months after sheep are removed from them, and that the 
infection is not destroyed by cold weather. They show, howerer, that during a winter with more or less freezing weather there is likely to be little or no increase in the amount of infeotion in pastures occupied by infested sheep. The eggs passed in the feces of the sheep will either be killed at once by freezing, or, on account of low temperatures above freezing, will remain dormant or develop so slowly that they are killed later by frost before they have reached the final larval stage, which is resistant to cold. At the same time, while the infestation of pastures may not be increased during the winter, the infestation of the sheep may be added to by their picking up from time to time larval worms which, prior to the beginning of cold weather, had developed already to the stage in which they are able to withstand freezing.

If sheep, goats, and cattle are kept off a pasture for a year, it is fair to assume, upon the basis of our present knowledge, that all, or practically all, larval stomach worms will have died within that time. There is also little doubt that the period required for the practical disinfection of a pasture may be shortened considerably by plowing it and placing it under cultivation.

Thus there are two ways by which a pasture may be freed of infestation, one by excluding sheep or other ruminants for at least a year, and the other by turning it into a cultivated field. In view of the fact that sheep placed on disinfected fields or pastures probably will not be entirely free from infestation, it is not of much consequence whether every larval stomach worm in the pastures is dead or not. The approximation to this point, which is attained by vacating pastures for a year or by plowing them up, is sufficient for practical purposes.

\section{WHAT METHODS CAN BE EMPLOYED TO PREVENT LOSS FROM STOMACH WORMS?}

It is barely possible that some means of artificially producing in lambs an immunity against the evil effects of stomach worms may be devised, but at the present time it is only a matter for speculation and experimental research. Our present knowledge of the stomach worm leads us to direct our efforts toward bringing about freedom from infestation or, as the next best thing, reducing the amount of infestation to a minimum and keeping it there.

\section{EARLY DEVELOPMENT OF LAMBS.}

One great step toward evading the stomach worm is found in the plan of having lambs dropped early and feeding to develop them as much as possible before they go to pasture.

Where sheep graze during winter and spring there is little danger of infestation in freezing weather, as the egrrs or young larva are killed 
before they are taken up by the lambs. There is but very slight danger that young lambs will become affected seriously while running with older sheep in barns or yards free from vegetation. Early lambing, combined with good feeding of the ewes to make them milk well, or of the lambs themselves in a "creep," or with both, brings early lambs to marketable weight and finish before the most dangerous part of the summer. Where lambs must remain for several months on pasture, frequent changing of pasture must be resorted to, to keep infestation below the extent that is injurious.

\section{A PRaCticable method of pasture rotation.}

The means of preventing the stomach-worm larvæ from getting into the lambs is suggested by what has been said concerning its development and powers of resistance. It was stated that a pasture that had been occupied by wormy sheep would need to be for at least a year without cattle, sheep, or goats in order to become practically free from stomach-worm larvæ.

From 10 to 20 days, according to temperature and moisture, must intervene between the dropping of the feces containing stomachworm eggs and the development of many of the larvæ to a point where they will develop into adult worms after being swallowed. If sheep are moved to a fresh pasture before the eggs in their droppings develop into mature larvæ, complete health can be maintained. The practical difficulty lies in always having a fresh pasture available. If only permanent grass pasture were used, adequate control would call for as many separate pastures as would allow the flock to be moved at least every 2 weeks without going on the same ground twice within 12 months. The time of grazing during freezing weather would not be included in such a plan, as few of the eggs or young larvæ would survive. It should be observed that it is not simply the changing of pastures that is called for, but changing to clean ground. Putting infested sheep on pasture in May, removing them during June and returning them in July, offers an excellent chance for infestation from the eggs dropped during the first pasturing which would have hatched out into young worms waiting to be taken up.

Some modifications of such a plan are quite practicable on any farm. In the first place, the danger is greatest to the lambs, and after they are sold or separated the ewes may go back to pastures used earlier in the season with much less danger of injury than would be incurred by the lambs. This change, however, would render that pasture unsafe for young lambs during the following spring. Hayfields, grain stubble, and oornfields can be utilized in the rotation of fields to furnish fresh grazing. 
Plowing the land infested with the larvæ of stomach worms greatly reduces the danger of infection. This fact allows the same land to be used two or three times for sheep in a season by using forage crops. Fall-sown wheat can be used for the earliest period, the land broken and resown to peas and oats, rape, or soy beans for a later grazing, and in some cases plowed again and sown to wheat to furnish late-fall feed. A succession of such crops is particularly desirable for carrying over from weaning time until winter the ewe lambs that are to be retained in the flock.

Where sufficient changes of pasture and fresh ground ean not be provided, preventive dosing may be partially relied upon. The danger in depending upon treatment lies in the fact that while cures usually can be effected by its proper use, lambs that have been allowed to reach the point where medicine is needed have at least been seriously checked in growth, and unless very carefully watched some deaths will occur.

The treatment oan be used as a measure to hold the stomach worms in check, in conjunction with rotation of pastures. Many successful shepherds dose all the ewes before turning them on the spring pastures with the lambs. This greatly lessens the number of eggs dropped. Afterwards all the lambs to be kept are similarly treated at the time of weaning, and individual cases may be treated on the first appearance of symptoms which will be noted if the flock receives the attention it really requires. When pasture rotation and similar preventive measures are impossible, sheep may be given the copper-sulphate treatment, preferably in diminished dosage, every month or 6 weeks during the summer season.

The stomach worm need not be a serious trouble for a good shepherd who has his lambs come early, feeds well, drenches the flock as a measure of prevention, and provides a rotation of pastures or pasture crops. 


\section{PUBLICATIONS OF THE U. S. DEPARTMENT OF AGRICULTURE RELAT. ING TO DISEASES OF LIVE STOCK.}

\section{PUBLICATIONS AVAILABLE FOR FREE DISTRIBUTION.}

Exterminating the Texas Fever Tick. (Farmers' Bulletin 498.)

Texas, or Tick Fever. (Farmers' Bulletin 569.)

Foot-and-Mouth Disease. (Farmers' Bulletin 666.)

Sheep Scab. (Farmers' Bulletin 713.)

Tuberculosis of hogs. (Farmers' Bulletin 781.)

Anthrax, or Charbon. (Farmers' Bulletin 784.)

The Sheep Tick: Its Eradication by Dipping. (Farmers' Bulletin 798.)

Screw-worms and Other Maggots. (Farmers' Bulletin 857.)

Swine Management. (Farmers' Bulletin 874.)

Cattle Lice and How to Eradicate Them. (Farmers' Bulletin 909.)

Important Poultry Diseases. (Farmers' Bulletin 957.)

Spinose Eartick, Treatment for. (Farmers' Bulletin 980.)

Cattle Scab and Methods of Control. (Farmers' Bulletin 1017.)

Hemorrhagic Septicemia: Stockyards Fever, Swine Plague, Fowl Cholera, etc. (Farmers' Bulletin 1018.)

Cerebrospinal Meningitis. (Department Bulletin 65.)

Vesicular Stomatitis of Horses and Cattle. (Department Bulletin 662.)

Necrotic Stomatitis, with Special Reference to Its Occurrence in Calves, Calf Diphtheria, and Pig Sore Mouth. (Bureau of Animal Industry Bulletin 67.)

Diseases of Stomach and Bowels of Cattle. (Bureau of Animal Industry Circular 68.) Actinomycosis, or Lumpy Jaw. (Bureau of Animal Industry Circular 96.)

PUBLICATIONS FOR SALE BY THE SUPERINTENDENT OF DOCUMENTS, GOVERNMENT PRINTING OFFICE, WASHINGTON, D. C.

Dog as a Carrier of Parasites and Diseases. (Department Bulletin 260.) Price 5 cents.

Control of Hog Cholera, with Discussion of Results of Field Experiments. (Department Bulletin 584.) Price 5 cents.

Laws (Federal, State, and Territorial), Relating to Contagious and Infectious Diseases of Animals. (Bureau of Animal Industry Bulletin 54.) Price 5 cents.

Gid Parasite, Its Presence in American Sheep. (Bureau of Animal Industry Bulletin 66.) Price 5 cents.

Studies of Blood and Blood Parasite of American Cattle. (Bureau of Animal Industry Bulletin 119.) Price 5 cents.

Nematodes Parasitic in Alimentary Tract of Cattle, Sheep, and Other Ruminants, (Bureau of Animal Industry Bulletin 127.) Price 20 cents.

A Comparative Study of Methods of Examining Feces for Evidence of Parasitism. (Bureau of Animal Industry Bulletin 135.) Price 10 cents.

Dourine of Horses, Its Cause and Suppression. (Bureau of Animal Industry Bulletin 142.) Price 15 cents.

Trypanosoma American, a Common Blood Parasite of American Cattle. (Bureau of Animal Industry Bulletin 145.) Price 5 cents.

The Action of Anthelmintics on Parasites Located Outside of the Alimentary Canal. (Bureau of Animal Industry Bulletin 153.) Price 5 cents.

Roundworms of Domestic Swine, with Special Reference to Two Species Parasitic in the Stomach. (Bureau of Animal Industry Bulletin 158.) Price 10 cents. 
12 Department Gircular 47, U. S. Department of Agriculture.

The Life History of Habronema Muscae, a Parasite of the Horse Transmitted by the House Fly. (Bureau of Animal Industry Bulletin 163.) Price 10 cents.

Diseases of the Stomach and Bowels of Cattle. (Bureau of Animal Industry Circular 68.) Price 5 cents.

Mycotic Lymphangitis of Horses. (Bureau of Animal Industry Circular 155.) Price 5 cents.

Methods for the Eradication of Gid. (Bureau of Animal Industry Circular 165.) Price 5 cents.

Measles in Cattle. (Bureau of Animal Industry Circular 214.) Price 5 cents.

Special Report on Diseases of Cattle. Price $\$ 1$.

Special Report on Diseases of Horses. Price $\$ 1$.

Special Report on History and Condition of Sheep Industry of the United States. Price $\$ 1.40$.

O 


\title{
STOMACH WORMS IN SHEEP PREVENTION AND TREATMENT
}

\author{
Prepared Jointly by the Animal Husbandry \\ and Zoological Divisions
}

\section{UNITED STATES DEPARTMENT OF AGRICULTURE DEPARTMENT CIRCULAR 47}

\author{
Contribution from the Bureau of Animal Industry \\ JOHN R. MOHLER, Chief
}





\section{STOMACH WORMS IN SHEEP:}

\section{PREVENTION AND TREATMENT.}

CONTENTS.

Page.

How can one tell when sheep have stomach worms? . . . . . . . .

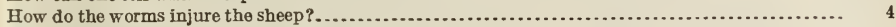

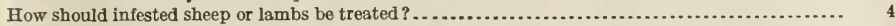

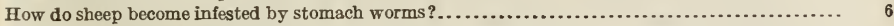

What methods can be employed to prevent loss from stomach worms? ....................... 8

NE of the most serious problems of owners of farm sheep is the prevention of injury and loss by stomach worms. This parasite (Hæmonchus contortus) has been known in this country for many years and is common in farm flocks, particularly during wet summers. It has been studied by the Zoological Division of the Bureau of Animal Industry and the principal facts in its life history have been determined. Ifethods of treatment and of prevention are still under investigation by that division, and although the methods have not yet been perfected, what has been learned is sufficient to show how affected sheep or lambs can be treated successfully and, what is of greater importance, how they may be raised in such a way as practically to overcome the danger.

What is known of this parasite and the methods of prevention and control may be presented as answers to practical questions, as follows:

\section{HOW CAN ONE TELL WHEN SHEEP HAVE STOMACH WORMS?}

Either lambs or old sheep may be affected by stomach worms at any time of the year. The trouble may be noticed first in lambs about the middle of summer, though it may be earlier, according to the part of the country and the temperature and moisture of the season.

In many flocks the first knowledge of the trouble is gained through the death of one or more lambs. If the flock is under careful observation, however, signs of stomach-worm disease will be noticed earlier. Dullness and lack of thrift are among the first indications. Scouring is often present. These conditions may result from other causes, but when due to stomach worms, they are accompanied with a very pale, bloodless appearance of the skin and of the mucous membranes of the eyes and mouth. The whiteness of the skin has caused the trouble to be known in some sections as "paper skin." In many cases there is a watery swelling under the jaws. 
Doubt as to the cause of the trouble can be removed by an examination of the fourth stomach. For examination purposes, any one unfamiliar with the ailment can well afford to kill an affected lamb. If there is any uncertainty as to the position of the fourth stomach it can be ascertained by taking hold of any part of the small intestine and following it forward. The fourth stomach is one of the 4 compartments into which the stomach is divided and is the portion continuous with the forward end of the small intestine. When the fourth stomach is found, it should be held so as to prevent the fluids from leaving it at either end, and an incision made along nearly the full length of the upper part. When this is done the stomach worms, if present, can be seen, often in large numbers, wriggling around in the fluids. They are from one-half to $1 \frac{1}{4}$ inches long, about as thick as an ordinary pin, and spirally striped with red and white. It is often necessary to look closely for some time in order to distinguish them. When the stomach is emptied some of the worms can be seen adhering to the inside walls.

\section{HOW DO THE WORMS INJURE THE SHEEP?}

The injurious action of the stomach worms may be attributed to two things: First, the loss of blood abstracted by the parasites, and second, the destruction of red corpuscles by a poisonous substance which is secreted by the parasites and taken up by the blood. Evidently the older, stronger, and larger sheep are better able than the lambs to withstand the loss of blood, and can better endure the loss due to the destruction of red corpuscles. Furthermore, in the blood of adult sheep there may be substances tending to neutralize the poisonous matter produced by the parasites that are absent from the blood of lambs, or that, if present, occur in smaller quantities. Besides the direct injury caused by stomach worms it is not unlikely that damage is also done by bacterial infection through the wounds the worms make in the mucous lining of the stomach.

\section{HOW SHOULD INFESTED SHEEP OR LAMBS BE TREATED?}

\section{MEDICINAL TREATMENT.}

If taken in time, most cases of stomach worms can be treated successfully according to the following directions:

Dissolve one-fourth pound (avoirdupois) of the powdered crystals of copper sulphate (bluestone) in 1 pint of boiling water, using a porcelain or enamel-ware dish, as the bluestone corrodes most metals. Then add cold water enough to make the solution up to 3 gallons, using wooden, earthenware, or other nonmetallic receptacles. This will make approximately a 1 per cent solution and will be euough to dose 100 artult sheep, allowing 10 per cent waste. In the preparation of the dose use only clear-blue crystals of copper sulphate. Crush the crystals to a fine powder when ready to make up the solution. 
The doses for lambs and sheep are:

For lambs under 1 year of age............... $1 \frac{3}{4}$ ounces (50 cubic centimeters). For sheep past 1 year old .................. $3 \frac{1}{2}$ ounces (100 cubic centimeters).

A glass with marks scratched on the side with a file may be used for measuring the doses.

The drenching apparatus consists of (1) a strong rubber tube about 3 feet long and three-eighths inch in diameter; (2) a hard rubber, porcelain, or enamel-ware funnel, which is fastened to one end of the tube; and (3) a brass mouthpiece three-eighths inch in diameter and 9 inches long, fastened to the other end. It is preferable that the end of this tube should be closed and holes made in the sides of about the last two inches of its length.

Ordinarily the treatment is given after the sheep have been without feed overnight, but apparently it may be given with equally good results without preliminary fasting, provided the animals are not gorged with feed or water when treated. For best results sheep should not be watered for 2 hours afterwards.

While being drenched the sheep should remain on all 4 legs with its head held horizontally. This is important, for if the head is held above the horizontal (nose higher than the eyes), there is danger that some of the fluid will pass into the lungs, thereby causing pneumonia and almost certain death. Measure the dose in the measuring glass, and after the drenching tube is in position pour the dose slowly into the funnel. The metal mouthpiece of the drenching tube should be placed between the jaws in the space between the teeth at the side of the mouth and directed backward, but should not reach farther than the base of the tongue. In order to prevent the sheep from stopping up the end of the mouthpiece with its tongue and thus interfering with the flow of the liquid, the person holding the mouthpiece in the sheep's mouth should give it a rotary motion. This tends to keep the sheep swallowing, prevents plugging the tube, and also tends to keep the fluid from entering the lungs. The fluid should not be administered more rapidly than the sheep can swallow comfortably.

Care in the administration of the dose is highly important, as carelessness or any undue haste is liable to have serious results. The copper-sulphate treatment, like the administration of medicines in general, is safest in the hands of a competent veterinarian.

\section{CHANGE OF PASTURE NECESSARY FOR BEST RESULTS.}

Although losses from stomach worms in many cases may be minimized by repeated medicinal treatment without change of pasture, much better results can be obtained if the treated animals are placed on ground that is free or practically free from infection. It is still better to institute preventive measures before the results of stomach-worm infection become evident. A lamb that has been 
affected sufficiently to show the external effects of stomach worms has received a serious setback. Although it may recover and again be thrifty it has lost at least a month or 6 weeks of progress toward marketable weight and condition. The only safe and economical way of raising sheep where stomach worms are a factor is by managing the flock and pastures in a way to prevent a serious development of the trouble. In most localities the methods necessary for preventing stomach worms are at the same time those that need to be employed for most economical production. In order to follow these methods, particularly with respect to pasture rotation, the shepherd needs to know just how and when infection occurs.

\section{HOW DO SHEEP BECOME INFESTED BY STOMACH WORMS?}

INFESTED PASTURES.

In the adult sexual stage stomach worms are able to live and carry out their reproductive functions only in the alimentary canal of sheep or other ruminants, and practically only in the fourth stomach. Each female produces thousands of eggs, of microscopic size, which do not develop into adult worms in the body of the host in which they are deposited, but, without hatching, pass out of the intestine in the feces. In a few hours, days, or weeks, according as the temperature is high or low, these eggs, if they are not killed by drying or freezing (either of which is commonly fatal to them), hatch and the tiny embryonic stomach worms then develop to what may be termed the final larval or infectious stage. This later development likewise requires days or weeks, according to the temperature, and until the young worms have reached the infectious stage they appear to be fully as susceptible to freezing and drying as the eggs. Having reached the infectious stage, however, the worms are able to withstand long periods of dryness and severe cold, though some of them succumb comparatively early.

In the infeetious stage the young worms are very active in the presence of moisture, and rapidly orawl up blades of grass and other objects whenever the relative humidity of the air is at a maximum, provided the temperature is above $40^{\circ} \mathrm{F}$. or thereabout; below that temperature they are inactive. A decrease in the relative humidity, with the consecpuent evaporation of the moisture from the surface of grass blades and other objects, stops the migrations of the worms, and they become quiescent and remain in a condition of suspended animation wherever they happen to be at the time. During the next period of wet weather, dew, rain, or fog, the worms again becomo active and climb still higher on tho grass, from which they are better able to attain their final abode within the stomach of a sheep or cow than if they remuined on the ground. When swallowed by a sheep or other ruminant the young stomueh worm, if it has reached its final 
larval stage, whether active at the time or in a state of suspended animation, continues its development, and in the course of 2 or 3 weeks reaches maturity.

The length of life of individual worms in the stomach has not been determined. Infested sheep have been kept in pens with board floors, which were kept clean by sweeping and frequent scrubbingthe sheep being fed from raised racks and water being supplied in a trough which was frequently cleaned-for varying periods up to a maximum of 19 months, and at the end of these periods were found to be still infested, though the number of worms present was small.

As the possibility of reinfection by larval worms developing from eggs passed in the feces of these sheep was not entirely removed, though greatly minimized, the results obtained do not necessarily indicate that the worms found at the end of the period of observation were all present when the experiment was begun. The experiment, however, while it proves nothing as to the length of life of the arlult stomach worm, demonstrates the futility of attempting to rid sheep entirely of stomach worms simply by keeping them away from pasture. On the other hand, very little infection oocurs among sheep kept in stables if eleanly conditions are maintained. Lambs have been kept with infested sheep in stables for long periods of time, the only precautions against infection being the removal of manure about once a week. Under such conditions they have continued in good health, and acquired only a very few stomach worms and other parasites.

LENGTH OF TIME PASTURES MAY BE INFESTED.

The maximum period during which the larval stomach worms are able to survive on pastures is not definitely known, but it has been found that pastures on which infested sheep had grazed were apparently still infectious after a lapse of neariy 8 months, namely, from October 25, when the infested sheep were removed, to June 16, when the pastures were tested by placing in them some lambs which had been raised under special precautions to avoid previous infestation. In cultures made September 14, 1906, from the feces of an infested sheep and kept thereafter in the laboratory, most of the larvæ were dead but some were still alive, though very sluggish, on June 5, 1907, nearly 9 months later. Cultures in which the worms were allowed to develop to the final larval stage, af ter they were kept in cold storage at a temperature below freezing-in some cases as low as $12^{\circ} \mathrm{F}$.still contained some living worms after 2 or 3 months, while in other cultures eggs and newly hatched worms not yet developerl to the final larval stage were killed within a few hours after exposure to temperatures below freezing.

These experiments show that pastures may remain infected for several months after sheep are removed from them, and that the 
infection is not destroyed by cold weather. They show, however, that during a winter with more or less freezing weather there is likely to be little or no increase in the amount of infeotion in pastures oocupied by infested sheep. The eggs passed in the feces of the sheep will either be killed at once by freezing, or, on aocount of low temperatures above freezing, will remain dormant or develop so slowly that they are killed later by frost before they have reached the final larval stage, which is resistant to cold. At the same time, while the infestation of pastures may not be increased during the winter, the infestation of the sheep may be added to by their picking up from time to time larval worms which, prior to the beginning of cold weather, had developed already to the stage in whioh they are able to withstand freezing.

If sheep, goats, and cattle are kept off a pasture for a year, it is fair to assume, upon the basis of our present knowledge, that all, or practically all, larval stomach worms will have died within that time. There is also little doubt that the period required for the practical disinfection of a pasture may be shortened considerably by plowing it and placing it under cultivation.

Thus there are two ways by which a pasture may be freed of infestation, one by excluding sheep or other ruminants for at least a year, and the other by turning it into a cultivated field. In view of the fact that sheep placed on disinfected fields or pastures probably will not be entirely free from infestation, it is not of much consequence whether every larval stomach worm in the pastures is dead or not. The approximation to this point, which is attained by vacating pastures for a year or by plowing them up, is sufficient for practical purposes.

\section{WHAT METHODS CAN BE EMPLOYED TO PREVENT LOSS FROM STOMACH WORMS ?}

It is barely possible that some means of artificially producing in lambs an immunity against the evil effects of stomach worms may be devised, but at the present time it is only a matter for speculation and experimental research. Our present knowledge of the stomach worm leads us to direct our efforts toward bringing about freedom from infestation or, as the next best thing, reducing the amount of infestation to a minimum and keeping it there.

EARLY DEVELOPMENT OF LAMBS.

One great step toward evading the stomach worm is found in the plan of having lambs dropped early and feeding to develop them as much as possible before they go to pasture.

Where sheep graze during winter and spring there is little danger of infestation in freezing weather, as the eggs or young larva aro killed 
before they are taken up by the lambs. There is but very slight danger that young lambs will become affected seriously while running with older sheep in barns or yards free from vegetation. Early lambing, combined with good feeding of the ewes to make them milk well, or of the lambs themselves in a "creep," or with both, brings early lambs to marketable weight and finish before the most dangerous part of the summer. Where lambs must remain for several months on pasture, frequent changing of pasture must be resorted to, to keep infestation below the extent that is injurious.

\section{a practicable method of pasture rotation.}

The means of preventing the stomach-worm larvæ from getting into the lambs is suggested by what has been said concerning its development and powers of resistance. It was stated that a pasture that had been occupied by wormy sheep would need to be for at least a year without cattle, sheep, or goats in order to become practically free from stomach-worm larvæ.

From 10 to 20 days, according to temperature and moisture, must intervene between the dropping of the feces containing stomachworm eggs and the development of many of the larvæ to a point where they will develop into adult worms after being swallowed. If sheep are moved to a fresh pasture before the eggs in their droppings develop into mature larvæ, complete health can be maintained. The practical difficulty lies in always having a fresh pasture available. If only permanent grass pasture were used, adequate control would call for as many separate pastures as would allow the flock to be moved at least every 2 weeks without going on the same ground twice within 12 months. The time of grazing during freezing weather would not be included in such a plan, as few of the eggs or young larvæ would survive. It should be observed that it is not simply the changing of pastures that is called for, but changing to clean ground. Putting infested sheep on pasture in May, removing them during June and returning them in July, offers an excellent chance for infestation from the eggs dropped during the first pasturing which would have hatched out into young worms waiting to be taken up.

Some modifications of such a plan are quite practicable on any farm. In the first place, the danger is greatest to the lambs, and after they are sold or separated the ewes may go back to pastures used earlier in the season with much less danger of injury than would be incurred by the lambs. This change, however, would render that pasture unsafe for young lambs during the following spring. Hayfields, grain stubble, and oornfields can be utilized in the rotation of fields to furnish fresh grazing. 
Plowing the land infested with the larvæ of stomach worms greatly reduces the danger of infection. This fact allows the same land to be used two or three times for sheep in a season by using forage crops. Fall-sown wheat can be used for the earliest period, the land broken and resown to peas and oats, rape, or soy beans for a later grazing, and in some cases plowed again and sown to wheat to furnish late-fall feed. A succession of such crops is particularly desirable for carrying over from weaning time until winter the ewe lambs that are to be retained in the flock.

Where sufficient changes of pasture and fresh ground can not be provided, preventive dosing may be partially relied upon. The danger in depending upon treatment lies in the faot that while cures usually can be effected by its proper use, lambs that have been allowed to reach the point where medicine is needed have at least been seriously cheoked in growth, and unless very carefully watched some deaths will occur.

The treatment oan be used as a measure to hold the stomach worms in oheok, in conjunction with rotation of pastures. Many successful shepherds dose all the ewes before turning them on the spring pastures with the lambs. This greatly lessens the number of eggs dropped. Afterwards all the lambs to be kept are similarly treated at the time of weaning, and individual cases may be treated on the first appearance of symptoms which will be noted if the flock receives the attention it really requires. When pasture rotation and similar preventive measures are impossible, sheep may be given the copper-sulphate treatment, preferably in diminished dosage, every month or 6 weeks during the summer season.

The stomaoh worm need not be a serious trouble for a good shepherd who has his lambs come early, feeds well, drenches the flock as a measure of prevention, and provides a rotation of pastures or pasture crops. 


\section{PUBLICATIONS OF THE U. S. DEPARTMENT OF AGRICULTURE RELAT. ING TO DISEASES OF LIVE STOCK.}

\section{PUBLICATIONS AVAllable FOR FREE Distribution.}

Exterminating the Texas Fever Tick. (Farmers' Bulletin 498.)

Texas, or Tick Fever. (Farmers' Bulletin 569.)

Foot-and-Mouth Disease. (Farmers' Bulletin 666.)

Sheep Scab. (Farmers' Bulletin 713.)

Tuberculosis of hogs. (Farmers' Bulletin 781.)

Anthrax, or Charbon. (Farmers' Bulletin 784.)

The Sheep Tick: Its Eradication by Dipping. (Farmers' Bulletin 798.)

Screw-worms and Other Maggots. (Farmers' Bulletin 857.)

Swine Management. (Farmers' Bulletin 874.)

Cattle Lice and How to Eradicate Them. (Farmers' Bulletin 909.)

Important Poultry Diseases. (Farmers' Bulletin 957.)

Spinose Eartick, Treatment for. (Farmers' Bulletin 980.)

Cattle Scab and Methods of Control. (Farmers' Bulletin 1017.)

Hemorrhagic Septicemia: Stockyards Fever, Swine Plague, Fowl Cholera, etc.

(Farmers' Bulletin 1018.)

Cerebrospinal Meningitis. (Department Bulletin 65.)

Vesicular Stomatitis of Horses and Cattle. (Department Bulletin 662.)

Necrotic Stomatitis, with Special Reference to Its Occurrence in Calves, Calf Diph-

theria, and Pig Sore Mouth. (Bureau of Animal Industry Bulletin 67.)

Diseases of Stomach and Bowels of Cattle. (Bureau of Animal Industry Circular 68.)

Actinomycosis, or Lumpy Jaw. (Bureau of Animal Industry Circular 96.)

PUBLICATIONS FOR SALE BY THE SUPERINTENDENT OF DOCUMENTS, GOVERNMENT PRINTING OFFICE, WASHINGTON, D. C.

Dog as a Carrier of Parasites and Diseases. (Department Bulletin 260.) Price 5 cents.

Control of Hog Cholera, with Discussion of Results of Field Experiments. (Department Bulletin 584.) Price 5 cents.

Laws (Federal, State, and Territorial), Relating to Contagious and Infectious Diseases of Animals. (Bureau of Animal Industry Bulletin 54.) Price 5 cents.

Gid Parasite, Its Presence in American Sheep. (Bureau of Animal Industry Bulletin 66.) Price 5 cents.

Studies of Blood and Blood Parasite of American Cattle. (Bureau of Animal Industry Bulletin 119.) Price 5 cents.

Nematodes Parasitic in Alimentary Tract of Cattle, Sheep, and Other Ruminants, (Bureau of Animal Industry Bulletin 127.) Price 20 cents.

A Comparative Study of Methods of Examining Feces for Evidence of Parasitism. (Bureau of Animal Industry Bulletin 135.) Price 10 cents.

Dourine of Horses, Its Cause and Suppression. (Bureau of Animal Industry Bulletin 142.) Price 15 cents.

Trypanosoma American, a Common Blood Parasite of American Cattle. (Bureau of Animal Industry Bulletin 145.) Price 5 cents.

The Action of Anthelmintics on Parasites Located Outside of the Alimentary Canal.

(Bureau of Animal Industry Bulletin 153.) Price 5 cents.

Roundworms of Domestic Swine, with Special Reference to Two Species Parasitic in the Stomach. (Bureau of Animal Industry Bulletin 158.) Price 10 cents. 
12 Department Circular 47, U. S. Department of Agriculture.

The Life History of Habronema Muscae, a Parasite of the Horse Transmitted by t House Fly. (Bureau of Animal Industry Bulletin 163.) Price 10 cents.

Diseases of the Stomach and Bowels of Cattle. (Bureau of Animal Industry Circu 68.) Price 5 cents.

Mycotic Lymphangitis of Horses. (Bureau of Animal Industry Circular 155.) Pr 5 cents.

Methods for the Eradication of Gid. (Bureau of Animal Industry Circular 16 Price 5 cents.

Measles in Cattle. (Bureau of Animal Industry Circular 214.) Price 5 cents. Special Report on Diseases of Cattle. Price $\$ 1$.

Special Report on Diseases of Horses. Price \$1.

Special Report on History and Condition of Sheep Industry of the United Stat Price $\$ 1.40$.

$\bigcirc$ 
Gaylord Bros.

Makers

Syracuse, N. Y.

PAT. JAN. 21, 1908

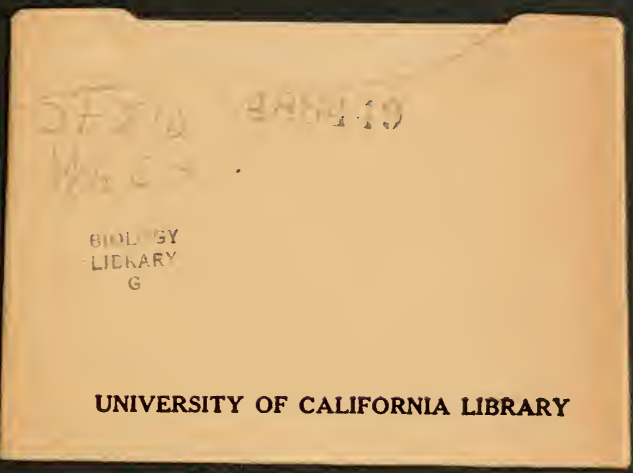


$\frac{1}{7}+4$

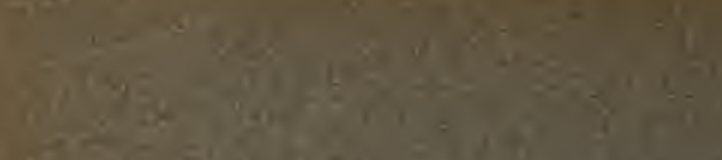

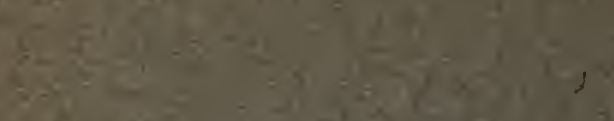

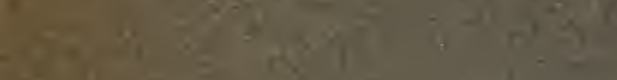

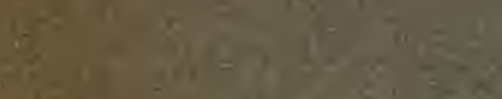

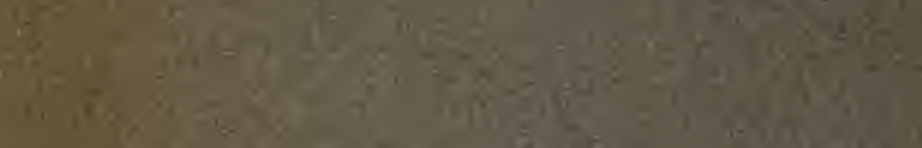

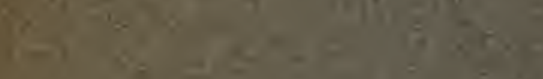

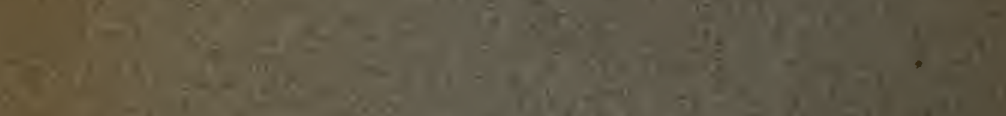

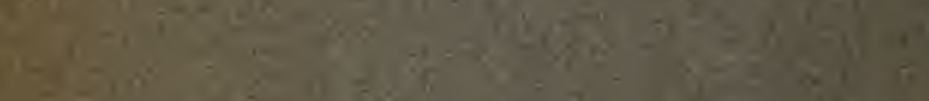

6.t.

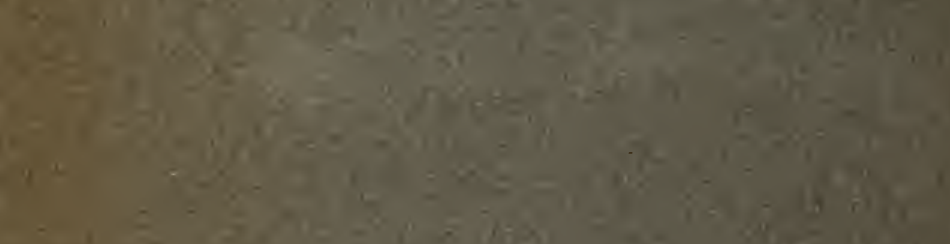

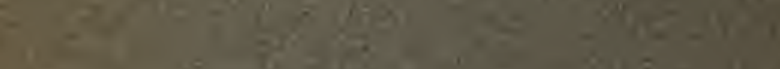

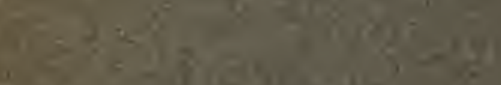

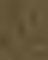

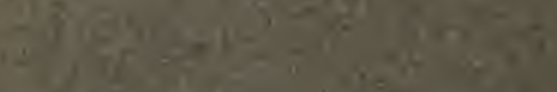

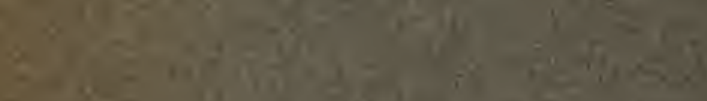

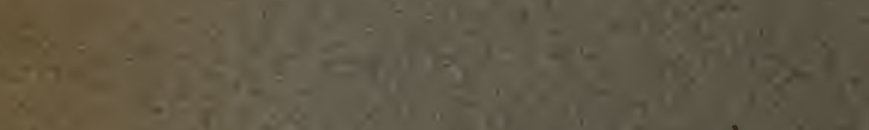

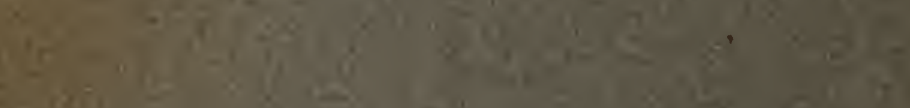

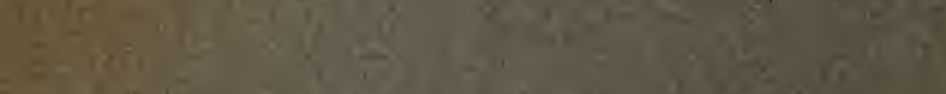

